Introduction: According to the literature, fluor-18-fluorodeoxyglucose positron emission tomography with computed tomography $\left({ }^{18} \mathrm{~F}-\mathrm{FDG}-\mathrm{PET}-\mathrm{CT}\right)$ is the most effective technique for the examination and detection of metastases in the lymph nodes in patients with cervical cancer. This study aimed to compare the diagnostic value of the preoperative evaluation using ${ }^{18} \mathrm{~F}-\mathrm{FDG}$ PET-CT with a histopathological examination of the lymph nodes removed during radical hysterectomy and pelvic lymph node dissection in patients with cervical cancer.

Material and methods: Retrospective analysis covered the medical records of 42 patients with cervical cancer (stage IA-IB according to International Federation of Gynaecology and Obstetrics 2009) treated with radical Piver type III hysterectomy and pelvic lymph node dissection. The preoperative diagnosis was made using a PET/CT examination. Results: The result of the ${ }^{18} \mathrm{~F}$-FDG-PETCT examination highlighted a suspicion of lymph node metastases in 13 patients (31\%). The histopathological examination confirmed this in 12 patients (29\%). Metastatic lymph nodes were correctly diagnosed using ${ }^{18}$ F-FDG-PET-CT in 8 out of the 12 cases confirmed by the histopathological examination. In the patient-based study, sensitivity, specificity, positive predictive value, negative predictive value and accuracy were $66.8 \%, 83.3 \%$, $61.5 \%, 86.2 \%$ and $78.6 \%$, respectively. Conclusions: We confirmed the usefulness of PET in the preoperative assessment of cervical cancer advancement, especially in correlation with the new 2018 International Federation of Gynaecology and Obstetrics staging system.

Key words: cervical cancer, lymph node metastases, positron emission tomography.

Contemp Oncol (Pozn) 2021; 25 (3): 160-167 DOI: https://doi.org/10.5114/wo.2021.109209

\section{Comparison of positron emission tomography with computed tomography examination with histopathological assessment of pelvic lymph nodes in patients with cervical cancer treated surgically}

\author{
Kamila Kaźmierczak ${ }^{1}$, Witold Cholewiński²,3, Błażej Nowakowski ${ }^{1}$
}

${ }^{1}$ Surgical, Oncological and Endoscopic Gynaecology Department, Greater Poland Cancer Centre, Poznań, Poland

2Electroradiology Department, Poznan University of Medical Sciens, Poznań, Poland ${ }^{3}$ Nuclear Medicine Department, Greater Poland Cancer Center, Poznań, Poland

\section{Introduction}

Despite the evident tendency of the number of new cases and deaths to decrease, cervical cancer is still one of the most common malignancies in women. Cervical cancer, which, after breast, colon, and lung cancers, is the fourth most common malignancy, is still a global problem [1].

The choice of treatment depends on the stage of clinical advancement assessed according to the International Federation of Gynaecology and Obstetrics (FIGO) staging system. However, the patient's age, coexisting diseases, results of imaging examinations and the preferences of both the patient and doctor are also considered [2].

The treatment methods of cervical cancer include surgery and radiation therapy as monotherapy or in combination with chemotherapy. In the qualification, which should be based on precise diagnostics, we should avoid the combination of radical surgery and radiation therapy, because these 2 methods significantly increase the frequency and severity of the adverse effects with no influence on the oncological results.

Until the end of 2018, the FIGO staging system used only of a physical examination and an X-ray image (X-ray, radioisotope thermoelectric generator) to confirm hydronephrosis. However, the above assessment was not validated during or after treatment. The 2009 FIGO staging system did not include the of lymph node metastases. This could result in inaccurate evaluation of the progression of the disease, which requires appropriate treatment.

In patients with cervical cancer, the presence of lymph node metastases is a negative prognostic factor. The 5-year patients' survival with metastatic paraaortic lymph nodes did not exceed 10-25\% [3].

In 2018, the FIGO staging system was extended by metastases to the pelvic and paraaortic lymph nodes as well as imaging examinations [4, 5].

Out of all imaging examinations available in the diagnosis of cervical cancer, the positron emission tomography with computed tomography (PET/CT) is considered the most effective method in detecting metastatic lymph nodes [6]. PET/CT is a morphological and important functional imaging method. For this purpose, the technique is based on the information obtained using a positron emitter labelled radiopharmaceutical distributed in the patient's body. Fluor-18-fluorodeoxyglucose positron emission tomography with computed tomography $\left({ }^{18} \mathrm{~F}-\mathrm{FDG}-\mathrm{PET}-\mathrm{CT}\right)$ is the marker most commonly used in cervical cancer. For better imaging, a combination of PET and computed to- 
mography CT or magnetic resonance imaging (MRI) is used. The advantages of PET/CT are the ability to perform a fullbody examination in a short time with little exposure to radiation and a low risk of adverse effects.

A meta-analysis by Choi et al., estimated the sensitivity and specificity of PET/CT in detecting lymph node metastases in cervical cancer at $82 \%$ and $95 \%$, respectively. Both parameters were lower obtained by computed tomography (50\% and 92\%) and MRI (56\% and 91\%) [6].

The evaluation of cervical cancer progression is very important to prepare an optimal treatment plan. According Burchardt et al. [7], in up to $30 \%$ of patients with cervical cancer the PET/CT may change the original therapeutic plan of radio/radiochemotherapy and surgical treatment. The aim of the study was to compare the diagnostic value of the preoperative evaluation using the ${ }^{18} \mathrm{~F}$-FDG-PET-CT with a histopathological examination of the lymph nodes removed during radical hysterectomy and pelvic lymph node dissection in patients with cervical cancer.

\section{Material and methods}

The retrospective study included 49 patients with cervical cancer treated surgically from 1

October 2011 to 31 March 2020. The stage of the disease was determined using the 2009 FIGO classification. The study enrolled patients at stage IA-IB2. The qualification for the treatment included routine laboratory tests, gynaecological examination, ultrasound vaginal examination and ${ }^{18}$ F-FDG-PET-CT. The basic treatment method applied in all patients was

Piver type III radical hysterectomy and pelvic lymph node dissection up to the level of aortic bifurcation. The analysis excluded 7 patients who had received preoperative neoadjuvant chemotherapy. Forty-two patients were included in further analysis. In all patients, ${ }^{18} \mathrm{~F}$-FDG-PET-CT was performed approximately 2 weeks before the surgery.

The technique of fluor-18-fluorodeoxyglucose positron emission tomography with computed tomography

The ${ }^{18} \mathrm{~F}$-FDG-PET-CT study was performed 60 minutes post-injection (p.i.) of the radiopharmaceutical ${ }^{18} \mathrm{~F}-\mathrm{FDG}$ with mean activity of $337 \pm 69$ megabecquerels $(\mathrm{MBq})$, range: 152-544 MBq (administered activity up to $3.7 \mathrm{MBq} / \mathrm{kg}$ of body mass). The ${ }^{18} \mathrm{~F}$-FDG-PET-CT study was performed using a Philips Gemini TF16 hybrid scanner (Philips, Cleveland, Ohio, USA). The acquisition protocol included the area of skull apex to mid-thigh (patients laid supine with arms above the head). PET imaging preceded body lowdose CT using the following parameters: 150-245 milliampere seconds (mAs), 120-140 kilovoltage peak ( $\mathrm{kVp}$ ), and pitch of 0.8. The PET section scanning time was $90 \mathrm{sec}-$ onds. The scanning time did not exceed 35 minutes.

Interpretation of the fluor-18-fluorodeoxyglucose positron emission tomography with computed tomography result

The description of the PET/CT examination considered the medical history, the result of gynaecological examina- tion and transvaginal ultrasound. An experienced specialist in nuclear medicine, who analysed the ${ }^{18} \mathrm{~F}$-FDG-PET-CT scans, was informed about the purpose of the examination. The ${ }^{18} \mathrm{~F}$-FDG-PET-CT result was considered negative when no areas of abnormal ${ }^{18} \mathrm{~F}-\mathrm{FDG}$ uptake were found. Any other site of the increased ${ }^{18} \mathrm{~F}-\mathrm{FDG}$ accumulation was described and classified as physiological, malignant, or ambiguous, depending on the size and intensity of tracer uptake. Malignant ${ }^{18} \mathrm{~F}$-FDG uptake was defined as that with an intensity higher than that of the surrounding tissues in the areas non-related to physiology. A PET/CT scan showing at least 1 malignant ${ }^{18} \mathrm{~F}-\mathrm{FDG}$ uptake site was considered positive. All the remaining areas of increased ${ }^{18} \mathrm{~F}$-FDG uptake were described as benign or unrelated to cancer when at the site of physiological uptake. Any other place that could not be clearly identified was described as ambiguous. PET/CT examinations with all the lesions defined as ambiguous or benign were respectively described as ambiguous or negative.

\section{Pelvic lymph node dissection}

All patients were subjected to therapeutic pelvic lymph node dissection up to the level of aortic bifurcation. The procedure was based on a complete removal of the lymphoid tissue from the common iliac vessels, both internal and external, as well as from the obturator fossa and the presacral space. In stage II, a radical Piver type III hysterectomy was performed.

\section{Histopathological evaluation of the lymph nodes}

All lymph nodes removed during therapeutic lymph node dissection were examined by an experienced pathologist. The lymph nodes were fixed with 10\% formalin and embedded in paraffin. Tissue sections were stained with haematoxylin and eosin. Histopathologically, the nodes were defined as positive (metastatic) or negative (no metastases).

\section{Statistical analysis}

The statistical analysis included descriptive statistics presented in the form of mean, standard deviation, median, the range of values for quantitative variables, and frequencies with percentages for categorical variables. Then, sensitivity, specificity, positive predictive value (PPV), negative predictive value (NPV), and accuracy for the PET/CT were calculated in relation to the results of histopathological examination. In the "patient-based" method, the following results were distinguished: true positive - the number of patients with metastases diagnosed usingthe ${ }^{18} \mathrm{~F}$-FDG-PET-CT, and then confirmed by the histopathological examination; false positive - the number of patients with a positive result of ${ }^{18} \mathrm{~F}$-FDG-PET-CT not confirmed by the histopathological examination; true negative - no metastases in the ${ }^{18} \mathrm{~F}$-FDGPET-CT or in the histopathological examination; and false negative - no metastases in the ${ }^{18} \mathrm{~F}$-FDG-PET-CT, found later in the histopathological examination. In the "region specific" method, the following results were distinguished: true positive - the number of metastatic nodes shown in the ${ }^{18} \mathrm{~F}$-FDG-PET-CT, and then confirmed in the histo- 
pathological examination; and false positive - the number of metastatic nodes diagnosed in the ${ }^{18} \mathrm{~F}$-FDG-PET-CT, but not confirmed by the histopathological examination; true negative - the number of all lymph nodes removed in patients with no suspicion of metastasis in the ${ }^{18} \mathrm{~F}-\mathrm{FDG}$ PET-CT and then assessed as metastasis-free in the histopathological examination; false negative - the number of metastatic nodes not found in the ${ }^{18} \mathrm{~F}-\mathrm{FDG}-\mathrm{PET}-\mathrm{CT}$, but revealed in the histopathological examination.

Moreover, the McNemar's test was performed to evaluate the consistency of the results obtained using the 2 methods.

The relationship between the presence of metastases (in the ${ }^{18}$ F-FDG-PET-CT and histopathological examination) and relapse of the disease was analysed using the Fisher's exact test.

\section{Results}

Piver type III radical hysterectomy and therapeutic pelvic lymph node dissection were performed in all patients enrolled in the study, and the ${ }^{18} \mathrm{~F}$-FDG-PET-CT was carried out prior to the surgery. Figure 1 shows an example of the results of the imaging examination.

The mean age of onset was $M=51.0$ years $(S D=11.8)$. $25.2(S D=4.61)$. The mean time to relapse was $M=19.8$ months $(S D=20.3)$ and the mean follow-up period was $M=37.6$ months $(S D=27.7)$. The mean number of removed lymph nodes removed was $M=28$ (SD = 10.2).
According to the 2009 FIGO staging system, 34 patients were classified as IB1 (81.0\%). Seven patients (16.7\%) were included in the IB2 group, and 1 patient (2.4\%) in the IA2 group. None of the subjects were assigned to the remaining groups. As for the histological type, 33 patients (78.6\%) had squamous cell carcinoma and 9 (21.4\%) adenocarcinomas.

The presence of lymph node metastases in the PET was found in 13 patients (31.0\%), while in 12 patients (28.6\%) they were reported in the histopathological examination. A relapse was noted in 6 patients (14.3\%) (Table 1). Both distant metastases (liver, small intestine, kidney) and local recurrence were found.

Diagnostic accuracy of the fluor-18fluorodeoxyglucose positron emission tomography with computed tomography in the detection of metastases to the lymph nodes in patients with cervical cancer

In 8 out of 12 cases, metastases to the lymph nodes were correctly diagnosed using ${ }^{18} \mathrm{~F}$-FDG-PET-CT. The results were confirmed by the histopathological examination. As for the total number of metastatic nodes shown in the PET/CT $(N=20)$, the findings were confirmed in 9 out of 22 cases (total number of metastatic nodes found in the histopathological examination).

Figure 2 shows an example of the lymph node metastases.

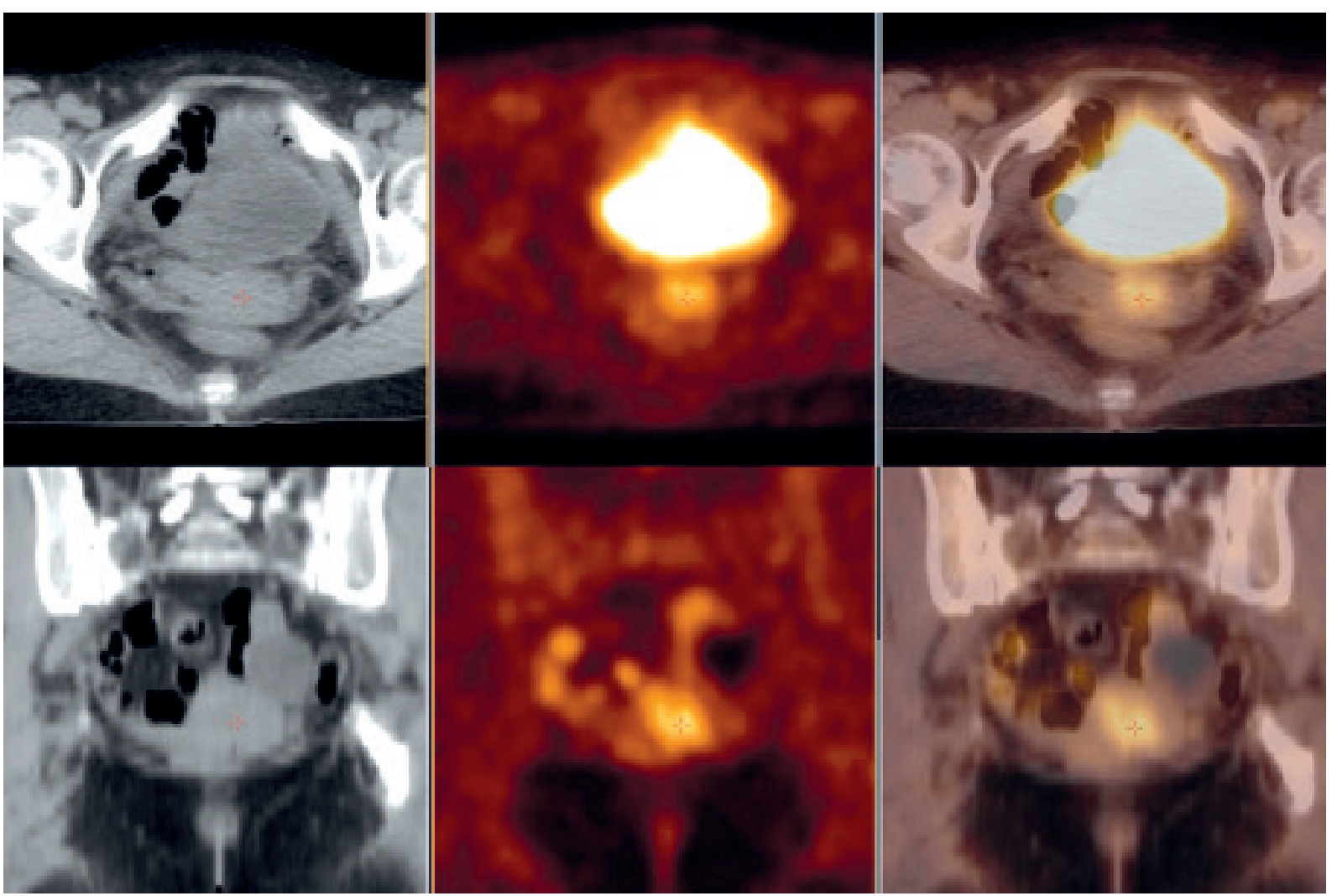

Fig. 1. Abnormal area of increased fluor-18-fluorodeoxyglucose uptake in the cervix consistent with cancer infiltration. Axial view (upper row) and coronal view (lower row) of the whole body fluor-18-fluorodeoxyglucose positron emission tomography with computed tomography over the pelvis - low-dose computed tomography (CT, left hand side images), positron emission tomography (PET, middle images) and PET/CT fusion (right-hand side images) 
Total sensitivity, specificity, PPV, NPV, and patient-based accuracy were $66.8 \%, 83.3 \%, 61.5 \%, 86.2 \%$, and $78.6 \%$, respectively. In the "region-specific" study, the same parameters reached the following values: $45 \%, 98.6 \%, 50 \%$, $98.4 \%$ and $58.5 \%$, respectively. Detailed results are presented in Table 2. Figure 3 shows an example of a false negative PET result verified as metastatic lymph nodes.

The McNemar's test confirmed that the results of the PET and the histopathological examination were consistent in the detection of metastases to the lymph nodes $-\chi^{2}(1)=0.11, p=0.739$

\section{Metastases to the lymph nodes}

in the histopathological examination,

fluor-18-fluorodeoxyglucose positron

emission tomography with computed

tomography and the risk of recurrence

No patient diagnosed with metastases to the lymph nodes in the PET/CT, which was then confirmed by the histopathological examination, was diagnosed with recurrence during the follow-up period. On the other hand, in patients with no metastases - true negative $(n=34)$, the disease relapsed in 6 cases. The analysis conducted using Fisher's exact test revealed no significance $(p=0.576)$, and thus no relationship between the variables. Interestingly, after including false positive results of the PET/CT (additionally 5 results, 8 confirmed by the histopathological examination), it transpired that 3 out of 13 patients with a positive result (true or false) had a relapse. In this case, the result of the Fisher's exact test was still insignificant ( $p=0.353)$.

The relationship between the presence of metastases diagnosed by the histopathological examination $(n=12)$ and recurrence of the disease also turned out to be statistically insignificant with $p=0.159$, both in these patients $(n=0)$ and those with no metastasis and a relapse $(n=6)$.

The diagnosis of metastases to the lymph nodes in the histopathological examination and adjuvant treatment

Systemic adjuvant treatment was used in the patients with lymph node metastases found in the histopathological examination.

The study confirmed that most patients diagnosed with lymph node metastases in the postoperative histopathological examination underwent adjuvant treatment. Among 12 patients with lymph node metastases, chemotherapy was applied in 9 cases (75.0\%) (Table 3 ).

\section{Discussion}

Cervical cancer most often invades the pelvic lymph nodes. The patients who participated in the study were qualified for surgical treatment, which enabled postoperative histopathological evaluation of these lymph nodes. The complete lymphadenectomy allowed us to quantify the occurrence of metastatic lymph nodes.

The main role of PET/CT in preoperative diagnostics was to exclude metastases to regional lymph nodes to avoid situations in which patients after surgical treatment are qualified for adjuvant radio/radiochemotherapy. Multi-module treatment for cervical cancer not only does
Table 1. Patients characteristics

\begin{tabular}{|c|c|c|c|}
\hline Characteristics $(n=42)$ & Number & Percentage & \\
\hline \multicolumn{4}{|l|}{ Age of onset (years) } \\
\hline Mean (SD), median & \multicolumn{3}{|c|}{51.0 (11.8), 49.0} \\
\hline Range & \multicolumn{3}{|c|}{$32-75$} \\
\hline \multicolumn{4}{|l|}{ BMI } \\
\hline Mean (SD), median & \multicolumn{3}{|c|}{$25.2(4.6), 25.0$} \\
\hline Range & \multicolumn{3}{|c|}{$18-39$} \\
\hline \multicolumn{4}{|l|}{ FIGO (2009) } \\
\hline $\mathrm{IA} 2$ & 1 & & 2.4 \\
\hline IB1 & 34 & & 81.0 \\
\hline IB2 & 7 & & 16.7 \\
\hline \multicolumn{4}{|l|}{ Histological type of cancer } \\
\hline Squamous cell carcinoma & 33 & & 78.6 \\
\hline Adenocarcinoma & 9 & & 21.4 \\
\hline \multicolumn{4}{|l|}{$\begin{array}{l}\text { Number of removed lymph } \\
\text { nodes }\end{array}$} \\
\hline Mean (SD), median & & 27.8 (10.2), 28.0 & \\
\hline Range & & $11-54$ & \\
\hline $\begin{array}{l}\text { Metastases to the lymph } \\
\text { nodes in PET (patients) }\end{array}$ & 13 & & 31.0 \\
\hline $\begin{array}{l}\text { Metastases to the } \\
\text { lymph nodes in the } \\
\text { histopathological } \\
\text { examination (patients) }\end{array}$ & 12 & & 28.6 \\
\hline Relapse & 6 & & 14.3 \\
\hline $\begin{array}{l}\text { Time to relapse (months) } \\
(n=6) \\
\text { Mean (SD), median }\end{array}$ & & 19.8 (20.3), 14.5 & \\
\hline Range & & $4-60$ & \\
\hline \multicolumn{4}{|l|}{ Follow-up period } \\
\hline Mean (SD), median & & $37.6(27.7), 34.0$ & \\
\hline Range & & $1-102$ & \\
\hline
\end{tabular}

$B M I$ - body mass index, SD - standard deviation

not improve treatment outcomes, and it significantly increases the number of complications and treatment costs.

A detailed summary of the study outcomes showed false-negative results of the ${ }^{18} \mathrm{~F}$-FDG-PET-CT in 4 patients and involved the lymph nodes with the size between $0.2 \mathrm{~cm}$ and $0.6 \mathrm{~cm}$ evaluated in the histopathological examination. In one patient, the preoperative ${ }^{18} \mathrm{~F}-\mathrm{FDG}$-PET-CT revealed increased metabolism suggesting a malignant process in one $5 \mathrm{~mm}$ pelvic lymph node. In the same patient, the postoperative histopathological examination showed 7 metastatic lymph nodes (the maximum size of $0.7 \mathrm{~cm}$ ) out of the 37 tested. The results of histopathological examinations confirmed reduced sensitivity of the ${ }^{18} \mathrm{~F}$-FDG-PET-CT in the diagnosis of metastatic lymph nodes depending on the size. According to Kitajimg et al., thesensitivity of the $\mathrm{PET} / \mathrm{CT}$ in the diagnosis of metastases to the lymph nodes in patients with cervical cancer was 100\% for metastatic lymph nodes $\geq 10 \mathrm{~mm} ; 67 \%$ for the nodes between 5 and $9 \mathrm{~mm}$ and $13 \%$ for nodal metastasis $\leq 4 \mathrm{~mm}$ [8].

However according to the new 2018 FIGO staging system, the presence of isolated neoplastic cells (diameter 


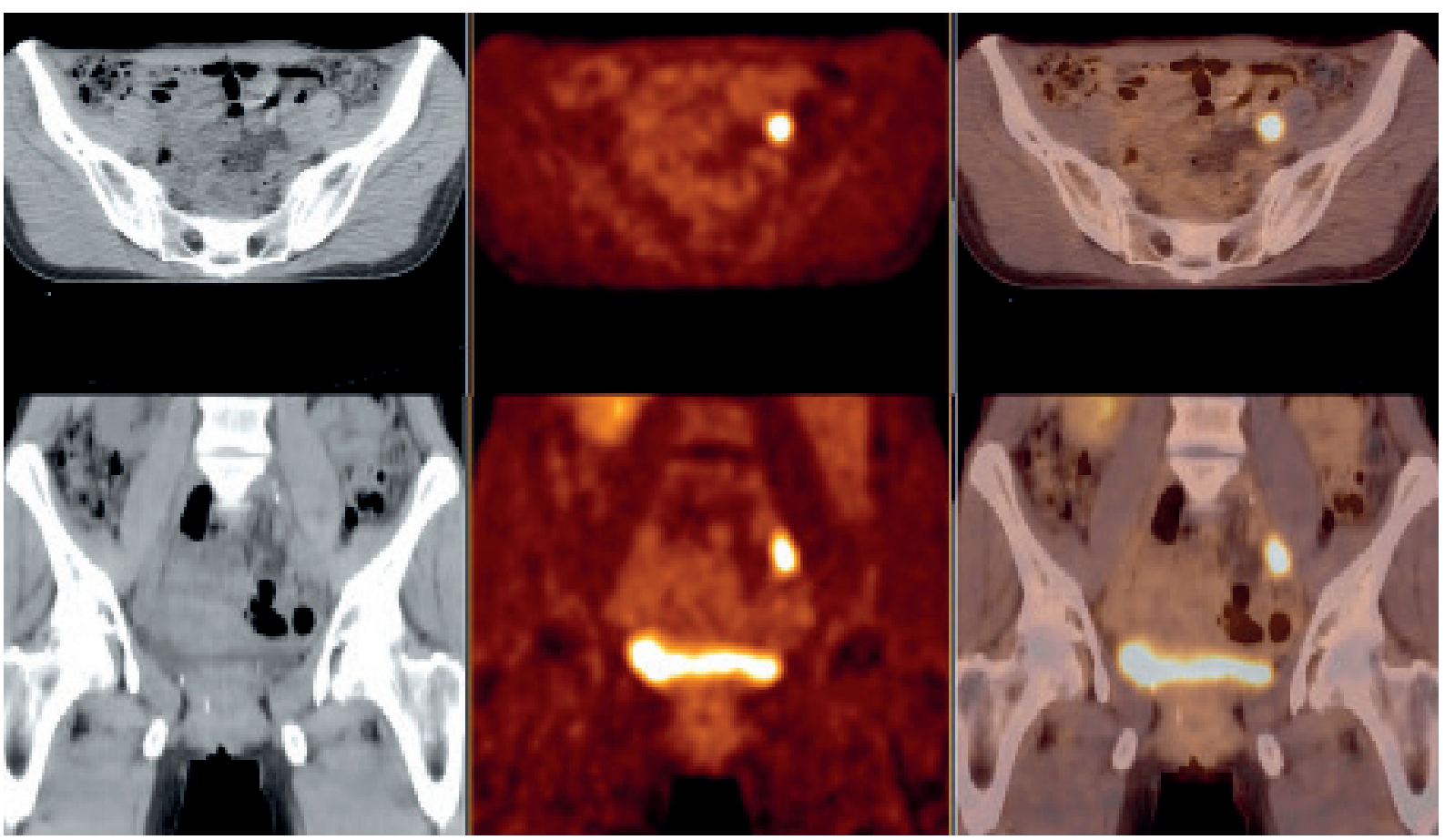

Fig. 2. Abnormal area of increased fluor-18-fluorodeoxyglucose positron emission tomography with computed tomography $\left({ }^{18} \mathrm{~F}-\mathrm{FDG}-\mathrm{PET}-\mathrm{CT}\right)$ uptake in the left iliac lymph node verified as metastatic. Axial view (upper row) and coronal view (lower row) of the whole body ${ }^{18}$ F-FDG-PET-CT over the pelvis - low-dose CT (left hand side image), PET (middle image), and PET/CT fusion (right hand side image)

Table 2. The accuracy of preoperative positron emission tomography with computed tomography in the detection of lymph node metastases in patients with cervical cancer

\begin{tabular}{|lcc|}
\hline Performance & $\begin{array}{c}\text { Patient-based } \\
\text { PET/CT }\end{array}$ & $\begin{array}{c}\text { Region-specific } \\
\text { PET/CT }\end{array}$ \\
\hline True positive $(n)$ & 8 & 9 \\
\hline True negative $(n)$ & 25 & 675 \\
\hline False positive $(n)$ & 5 & 9 \\
\hline False negative $(n)$ & 4 & 11 \\
\hline Sensitivity (\%) & $66.8 \%$ & 45 \\
\hline Specificity (\%) & $83.3 \%$ & 98.6 \\
\hline PPV (\%) & $61.5 \%$ & 50 \\
\hline NPV (\%) & $86.2 \%$ & 98.4 \\
\hline Accuracy (\%) & $78.6 \%$ & 58.5 \\
\hline
\end{tabular}

PPV - positive predictive value, NPV-negative predictive value, PET/CT - positron emission tomography with computed tomography

$<0.2 \mathrm{~mm}$ ) or micrometastases (diameter $0.2-2 \mathrm{~mm}$ ) in the lymph nodes does not change the stage of the disease. This fact should be reported in the medical records [4, 5].

A false-positive PET/CT result was obtained in $5 \mathrm{pa}$ tients in whom, despite the removal of 16, 34, 43, 41, and 32 lymph nodes, no metastases were found in the postoperative histopathological examination. The largest dimension of a lymph node with the increased glucose metabolism, which arouse a suspicion of metastasis in the PET/CT not confirmed by the histopathological examination, was $17 \mathrm{~mm}$, and the smallest was $5 \mathrm{~mm}$. Three of these patients were diagnosed with a relapse. This confirmed the results published by Chung et al., showing higher rates of recurrence $(3 / 8)$ in patients with a positive preoperative
PET/CT result than in those with negative scans $(1 / 26)$ [9]. Anyway, this result is interesting, but the reason is not clear-cut and requires further research.

Similarly to the study by Chung et al., we have found higher values of sensitivity and specificity of the PET/CT in the patient-based analysis compared to the regionspecific examination. These results are worse than those of the previous studies analysing the PET/CT result alone [10-12]. According to one of the latest meta-analyses of 2018 , the total diagnostic sensitivity and specificity of the PET-CT in the diagnosis of lymph node metastases in patients with cervical cancer were as follows: 0.72 ; $95 \% \mathrm{Cl}$ : $0.69-0.75$ and 0.96 ; $95 \% \mathrm{Cl}: 0.96-0.97$ [13].

There is also the added value of the ${ }^{18} \mathrm{~F}$-FDG-PET-CT in qualifying for surgical treatment those patients with locally advanced cervical cancer, because the examination provides important information on the possible long-term spread of cancer. In the multicentre study ACRIN 6671/ GOG 0233 MS., Gee et al., demonstrated high specificity (98\%), PPV (79\%) and sensitivity (55\%) in detecting distant metastases (non-regional lymph nodes, peritoneal, bone, liver and lung lesions) in patients with locoregional cervical cancer. Distant metastases were unexpectedly diagnosed in as many as $14 \%$ of patients [14]. In our study, during preoperative PET/CT examination, distant metastases were not diagnosed in the group of patients with locally advanced cervical cancer qualified for surgical treatment.

According to a meta-analysis conducted in 2019, the diagnostic value of PET/CT in detecting metastases to the para-aortic lymph nodes in patients with cervical cancer showed sensitivity and specificity of $95 \% \mathrm{Cl}$ : 0.54-0.83 and $95 \% \mathrm{Cl}: 0.93-0.98$, respectively [15]. 


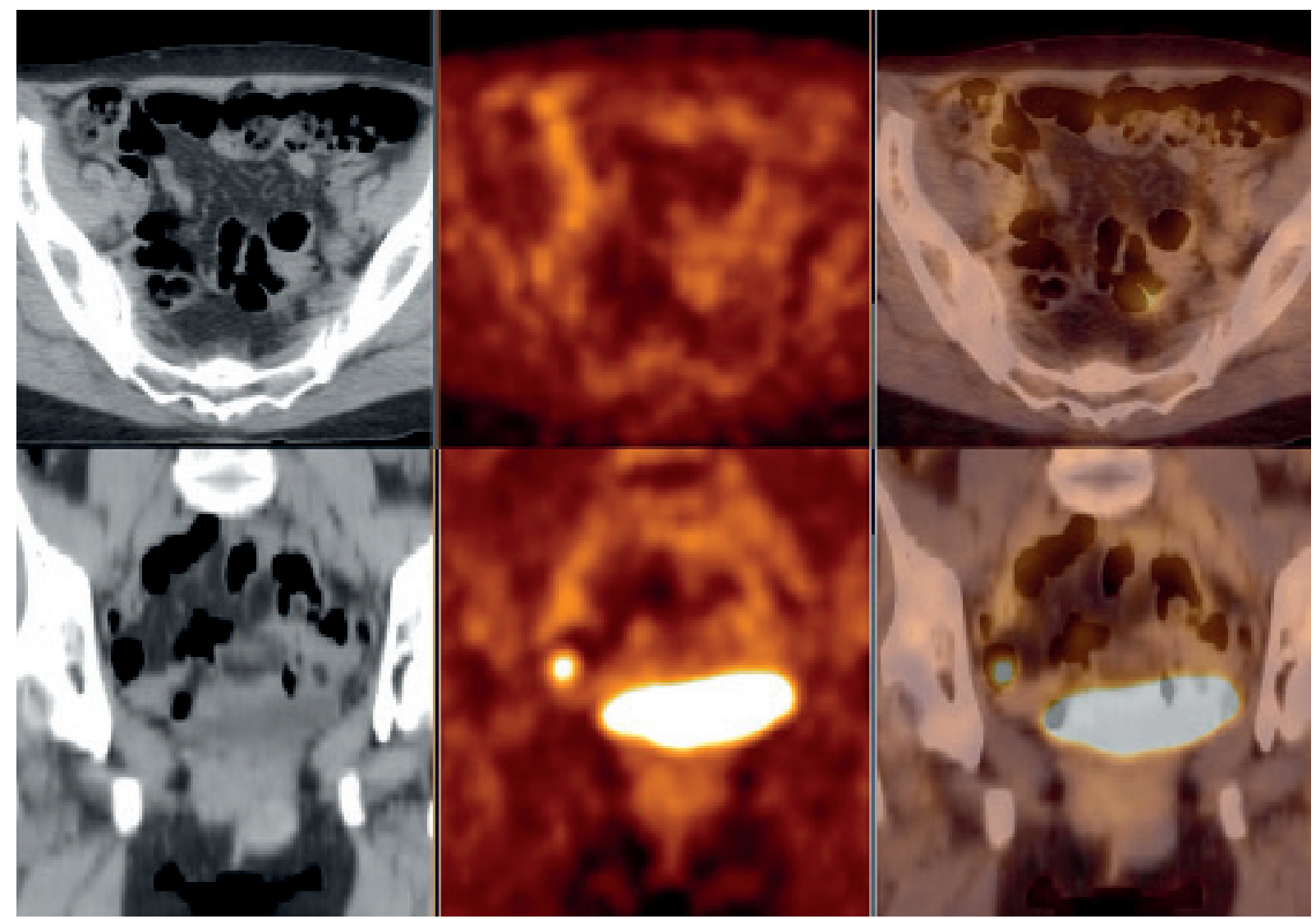

Fig. 3. Bilateral iliac lymph nodes with no fluor-18-fluorodeoxyglucose $\left({ }^{18} \mathrm{~F}-\mathrm{FDG}\right)$ uptake - false negative positron emission tomography (PET) findings verified as metastatic lymph nodes. Axial view (upper row) and coronal view (lower row) of the whole body fluor-18-fluorodeoxyglucose positron emission tomography with computed tomography $\left({ }^{18} \mathrm{~F}-\mathrm{FDG}-\mathrm{PET}-\mathrm{CT}\right)$ over the pelvis - low dose computed tomography (CT, left hand side image), PET (middle image) and PET/CT fusion (right hand side image)

The recommendations of scientific societies, such as the Polish Society of Gynaecological

Oncology, the European Society of Gynaecological Oncology (ESGO) and the National Comprehensive Cancer Network differ in terms of conditions for extending the clinical examination to include imaging techniques. To sum up, in advanced cervical cancer, pathological verification is needed, both in the presence and absence of suspected metastatic paraaortic lymph nodes. The histopathological verification allows a decision to be made whether radiation therapy should be extended to include this area. This management enables positive lymph nodes to be visualized, as well as avoiding irradiation without clinical indications [16-18].

According to the literature, the presence of metastatic pelvic and paraaortic lymph nodes is one of the most important prognostic factors of high probability of cervical cancer recurrence $[19,20]$. In recurrence of cervical cancer, the prognosis is poor because ineffective treatment of the primary lesion indicates a low probability of successful recurrence therapy [21, 22].

The fact that none of the 12 patients with metastatic lymph nodes in the postoperative histopathological examination showed recurrence in the follow-up is the added value of our analysis. Nine patients from this group were treated with adjuvant systemic treatment. Knowing the
Table 3. Metastases to the lymph nodes in the histopathological examination and adjuvant treatment

\begin{tabular}{|lccc}
\hline Adjuvant & \multicolumn{2}{c}{$\begin{array}{c}\text { Metastases to the lymph nodes - } \\
\text { histopathological examination }\end{array}$} & Total \\
\cline { 2 - 3 } & Positive & Negative & \\
\hline $\begin{array}{l}\text { Adjuvant } \\
\text { chemotherapy }\end{array}$ & 9 & 2 & 11 \\
\hline No adjuvant & 3 & 28 & 31 \\
\hline Total & 12 & 30 & 42 \\
\hline
\end{tabular}

condition of the lymph nodes in patients with cervical cancer allowed these patients to be subjected to a therapy adequate to the stage of the disease, which translated into treatment results.

At the beginning of our study, the 2009 FIGO staging system, which did not include the evaluation of the lymph nodes, was valid. The new 2018 FIGO classification was extended to include assessment of the lymph nodes, putting emphasis on the importance of metastatic lymph nodes as a major negative prognostic factor in cervical cancer. The diagnosis of lymph node involvement can be made based on a microscopic examination or radiological evaluation $[4,5]$.

The survival rates of patients with lymph node metastases are significantly worse than in nonmetastatic patients, and therefore detection of nodal lesions is essential for choosing the appropriate treatment and determining the 
prognosis in patients with cervical cancer. The 3-year survival rate in patients with the absence of nodal metastases during cervical cancer is estimated at 94\%, compared to $64 \%$ for patients with positive pelvic nodes and $35 \%$ for those with positive para-aortic nodes $[23,24]$.

Until the change of the FIGO staging system in 2018, the results of imaging examinations were not considered when determining the stage of cervical cancer. The sensitivity and specificity of the previously available imaging methods, such as CT and MRI, in the evaluation of lymph node metastases in patients with cervical cancer was low [25-28].

Currently, the preoperative PET/CT performed in patients with cervical cancer allows the stage of the disease to be determined and to choose the appropriate therapy to be chosen.

Nowadays, PET/CT imaging is the most effective method of imaging the lymph nodes [29]. In a retrospective study, Hansen et al., assessed the survival time in 2 groups of patients: the first group had the PET/CT performed before radiation therapy, and the second group was not subjected to such an examination. In the first group, there were significantly improved of 5-year survival and longer disease-free times, which was due to the detection of previously undiagnosed metastatic lymph nodes [6].

The comparison of the results of the imaging examination and the pathological test allowed for an objective evaluation of the effectiveness of PET/CT in the diagnosis of metastatic lymph nodes, and this is of great clinical importance in light of the current 2018 FIGO staging system.

None of the patients with nodal metastases found in the histopathological examination showed a relapse during the follow-up period. Most of this group underwent systemic treatment. However, the findings require further research.

\section{Conclusions}

Compared to other imaging methods, the diagnostic effectiveness of preoperative PET/CT examination in detecting metastatic lymph nodes in patients with cervical cancer is high although its accuracy is not explicit.

Despite the usefulness of PET/CT in the diagnosis of lymph node metastases in patients with cervical cancer, in light of the current guidelines and the 2018 FIGO staging system for cervical cancer, false positive results may appear and disqualify patients from surgical treatment.

\section{The authors declare no conflict of interest.}

\section{References}

1. International Agency for Reserch on Cancer - IARC, Globocan 2012. Estimated cancer in-cidence, mortality and prevalence worldwide 2015. Available on: http://globocan.iarc.fr.

2. FIGO Committee on Gynecologic Oncology. FIGO staging for carcinoma of the vulva, cervix, and corpus uteri. Int J Gynecol Obstet 2014; 125: 97-98.

3. Höckel M, Wolf B, Schmidt K, et al. Surgical resection based on ontogenetic cancer field theory for cervical cancer: mature results from a single-centre, prospective, observational, cohort study. Lancet Oncol 2019; 20: 1316-1326.

4. Bathla N, Berek JS, Cuello Fredes M, et al. Revised FIGO staging for carcinoma of the cervix uteri. Int J Gynecol Obstet 2019; 145: 129-135.

5. Lepka P, Jędryka M, Misiek M, Matkowski R, Zalewski K. Aktualizacja klasyfikacji stopni zaawansowania raka szyjki macicy - stan na 2019 rok. Curr Gynecol Oncol 2019; 17: 10-18.

6. Hansen HV, Loft A, Berthelsen AK, Christensen IJ, Høgdall C, Engelholm SA. Survival outcomes in patients with cervical cancer after inclusion of PET/CT in staging procedures. Eur J Nucl Med Mol Imaging 2015; 42: 1833-1839.

7. Burchardt E. Rola badania PET w leczeniu raka szyjki macicy w doniesieniach na 3rd ESTRO Forum 2015. Lett Oncol Sci 2017; 14: 33-38.

8. Kitajima K, Murakami K, Yamasaki E, Kaji Y, Sugimura K. Accuracy of integrated FDG-PET/contrast-enhanced CT in detecting pelvic and paraaortic lymph node metastasis in patients with uterine cancer. Eur Radiol 2009; 19: 1529-1536.

9. Chung HH, Park NH, Kim JW, Song YS, Chung JK, Kang SB. Role of integrated PET-CT in pelvic lymph node staging of cervical cancer before radical hysterectomy. Gynecol Obstet Invest 2009; 67: 61-66.

10. Grigsby PW, Dehdashti F, Siegel BA. FDGPET Evaluation of carcinoma of the cervix. Clin Positron Imaging 1999; 2: 105-109.

11. Rose PG, Adler LP, Rodriguez M, Faulhabe PF, Abdul-Karim FW, Miraldi F. Positron emission tomography for evaluating para-aortic nodal metastasis in locally advanced cervical cancer before surgical staging: a surgicopathologic study. J Clin Oncol 1999; 17: 41-45.

12. Grigsby PW, Perez CA, Chao KS, Herzog T, Mutch DG, Rader J. Radiation therapy for carcinoma of the cervix with biopsy-proven positive para-aortic lymph nodes. Int J Radiat Oncol Biol Phys 2001; 49: 733-738.

13. Ruan J, Zhang Y, Ren H. Meta-analysis of PET/CT detect lymph nodes metastases of cervical cancer. Open Med (Wars) 2018; 22: 436-442.

14. Gee MS, Atri M, Bandos Al, Mannel RS, Gold MA, Lee SI. Identification of distant metastatic disease in uterine cervical and endometrial cancers with FDG PET/CT: analysis from the ACRIN 6671/GOG 0233 Multicenter Trial Radiol 2018; 287: 176-184.

15. Yu W, Kou C, Bai W, et al. The diagnostic performance of PET/CT scans for the detection of para-aortic metastatic lymph nodes in patients with cervical cancer: a meta-analysis. PLoS One 2019; 18.

16. Jach R, Sznurkowski JJ, Bidziński M, et al. Recommendations of the Polish Gynecological Oncology Society for the diagnosis and treatment of cervical cancer. Curr Gynecol Oncol 2017; 15: 24-33.

17. Cibula D, Pötter R, Planchamp F, et al. The European Society of Gynaecological Oncology/European Society for Radiotherapy and Oncology/European Society of Pathology guidelines for the management of patients with cervical cancer. Radiother Oncol 2018; 127: 404-416.

18. NCCN. Guidelines verison4-cervicalcancer. National Comprehensive Cancer Network. Accessed, 2020. Available on: https://www. nccn.org/professionals/physician_gls/pdf/cervical.pdf

19. Leblanc E, Narducci F, Frumovitz M, et al. Therapeutic value of pretherapeutic extraperitoneal laparoscopic staging of locally advanced cervical carcinoma. Gynecol Oncol 2017; 18: 304-311.

20. Grigsby PW, Perez CA, Chao KS, Herzog T, Mutch DG, Rader J. Radiation therapy for carcinoma of the cervix with biopsy-proven positive para-aortic lymph nodes. Int J Radiat Oncol Biol Phys 2001; 49: 733-738.

21. Bodurka-Bevers D, Morris M, Eifel PJ, et al. Posttherapy surveillance of women with cervical cancer: an outcomes analysis. Gynecol Oncol 2000; 78: 187-193.

22. Waggoner SE. Cervical cancer. Lancet 2003; 361: 2217-2225.

23. Morice P, Castaigne D, Pautier P, et al. Interest of pelvic and paraaortic lymphadenectomy in patients with stage IB and II cervical carcinoma. Gynecol Oncol 1999; 73: 106-110.

24. Son SH, Jeong SY, Chong GO, et al. Prognostic value of pretreatment metabolic PET parameters in cervical cancer patients with metabolic complete response after concurrent chemoradiotherapy. Clin Nucl Med 2018; 43: 296-303.

25. Bellomi M, Bonomo G, Landoni F, et al. Accuracy of computed tomography and magnetic resonance imaging in the detection of 
lymph node involvement in cervix carcinoma. Eur Radiol 2005; 15: 2469-2474.

26. Choi HJ, Roh JW, Seo SS, et al. Comparison of the accuracy of magnetic resonance imaging and positron emission tomography/computed tomography in the presurgical detection of lymph node metastases in patients with uterine cervical carcinoma: a prospective study. Cancer 2006; 106: 914-922.

27. Sahdev A, Sohaib SA, Wenaden AE, Shepherd JH, Reznek RH. The performance of magnetic resonance imaging in early cervical carcinoma: a long-term experience. Int J Gynecol Cancer 2007; 17: 629-636.

28. Hertel H, Kohler C, Elhawary T, Michels W, Possover M, Schneider A. Laparoscopic staging compared with imaging techniques in the staging of advanced cervical cancer. Gynecol Oncol 2002; 87: 46-51.

29. Mayoral M, Paredes P, Domènech B, et al. F-18-FDG PET/CT and sentinel lymph node biopsy in the staging of patients with cervical and endometrial cancer. Role of dualtimepoint imaging. Rev Esp Med Nucl Imagen Mol 2017; 36: 20-26.

\section{Address for correspondence}

\section{Kamila Kaźmierczak}

Surgical, Oncological and Endoscopic Gynaecology Department Greater Poland Cancer Centre

Garbary 15 St.

61-866 Poznań, Poland

e-mail: kamilka35@icloud.com

Submitted: 21.07.2021

Accepted: 13.08.2021 